\title{
Measurement of Mean Arterial Pressure by Carotid Artery Cannulation in Isoflurane Anesthetized Wistar Rats
}

\author{
Sidonia Alina BOGDAN ${ }^{1}$, Vlad LUCA ${ }^{1}$, Cosmin PESTEAN ${ }^{1}$, Ciprian OBER ${ }^{1}$, Lucia BEL ${ }^{1}$, Andrei Razvan \\ CODEA $^{1 *}$, Ileana Bogdan ${ }^{2}$, Radu MANDEAL ${ }^{1}$, Liviu OANA ${ }^{1}$
}

${ }^{1}$ Department of Preclinical Sciences, University of Agricultural Sciences and Veterinary Medicine, ClujNapoca, Calea Manastur 3-5, 400372, Romania

${ }^{2}$ Departent of Technical and Soils Sciences, University of Agricultural Sciences and Veterinary Medicine, Cluj-Napoca, Calea Manastur 3-5, 400372, Romania

*corresponding author: razvancodea@yahoo.com

Bulletin UASVM Veterinary Medicine 74(1) / 2017,

Print ISSN 1843-5270; Electronic ISSN 1843-5378

DOI:10.15835/buasvmcn-vm: 12617

\begin{abstract}
Rats in particular are a widely-used model for experimental studies (Ordodi et al., 2004). Blood pressure measurement is one of the fastest and most informative means of assessing cardiovascular function and provides an accurate indication of drug effects, surgical events and hemodynamic trends (Tranquilli et al., 2007). A close monitoring of the animals during any experiment is important to detect early imbalances and prevent any changes that could compromise the results. Experimental surgery on small lab animals, especially rats, it's a widely used model. In order to perform surgery, anaesthesia must be used and it usually causes a slowdown of the respiration that induces metabolic imbalances. It could cause cardiovascular collapse and death if left unbalanced. A close monitoring of the respiration, ECG, blood pressure is necessary during the experiment (Ordodi et al., 2004). Because it may not be always available or the prohibitive cost of the special equipment used to perform these tasks, we adapted a simple device and method to record the mean arterial pressure (MAP) in rats by carotid catheterisation and the results obtained were sustainable. In our experiment, we present a simple method to record mean arterial pressure by carotid cannulation in anesthetised rats which can be easily performed and the materials needed are no others that the one used for other species.

A number of 10 rats were anesthetised with isoflurane and were surgically prepared in the ventral cervical area. The carotid artery was dissected and exposed by surgical techniques; an intravenous cannula was placed and connected to a transducer. This transforms the pressure from the blood flow in an electronic wave which is registered on the Dräger Infinity Delta monitor.
\end{abstract}

Keywords: carotid cannulation, mean arterial pleasure, rats

\section{INTRODUCTION}

The most frequently used animal in scientific inquiry conduced for the purpose ofadvancingbasic knowledge that may lead to an improvement is the rat. Inhalation anaesthesia offers better control and it has the ability to change rapidly the level of anaesthesia which makes it safer (Karwacki et al., 2006). Most of the experiments need anaesthesia and its application on rats requires modification of the equipment and technique due to small patient size, challenges of restrain, monitoring limitations and increased metabolism (Novak, 2003).

Inhalation anaesthetics are used widely for the anaesthetic management of animals. They are administrated via lungs and a large part is removed from the body by the same path. Their 
pharmacokinetic characteristics give them a lot of advantages like: they are predictable and the depth of the anaesthesia can be adjusted quickly. In addition, the specialapparatus thatisused to deliver the anaesthetic inhalant agent includes oxygen which sustains the breathing. Administration of anaesthetic drugs, the unconscious, recumbent, immobile state compromise patient homeostasis and is important to monitor the patient in order to detect the specific needs and to maximize the safety of the anaesthetic experience (Tranquilli et al., 2007).Patients who are anesthetized are placed at risk for hypotension. Close monitoring of blood pressure is vital, otherwise kidneys, heart and brain perfusion can be compromised, leading to organ dysfunction (Faunt et al., 2008). Isoflurane is a largely used anaesthetic in all species. Its depressive effects on cardiovascular system are less than injectable or other inhalant agents and it is dependent on the depth of the anaesthesia. Cardiac depression, contraction is minimal compared to other inhalant agents (Muir et al., 2008).

Maintaining the rats' vital functions within normal range during the anaesthesia is essential for the success of the experiment. Anaesthesia and experimental procedure affect the respiratory and cardiovascular system, could cause loss of fluids or induce traumatic shock and could compromise the procedure. During the experiment, all subjects must be closely monitored. Accurate information about function of the cardiovascular system during the intervention can help take prompt actions to correct the imbalances (Ordodi et al., 2004).

Blood pressure measurement is one of the basic procedures in biomedical research and it can be done by non-invasive or invasive techniques. The gold standard procedures with the most accuracy are the invasive techniques. This includes radial, femoral, brachial or carotid cannulation (Parasuraman et al., 2012). Carotid artery catheterization is a common procedure that allows precise monitoring of the blood pressure but surgery is required to perform (Plehm et al. 2006). There is a special equipment to perform these tasks on rats, but they may not be always available or they have prohibitive costs.

\section{MATERIALS AND METHODS}

The rats used in this study were kept in controlled conditions and received standard rat feed and water ad libitum. This experiment respects the bioethics roles implemented by the Ethics Committee of the University of Agricultural Sciences and Veterinary Medicine Cluj-Napoca.

The subjects, 10 rats, 5 males and 5 females were used to test this protocol. All subjects were clinically examined and were weight before the experiment. Inhalatory anaesthesia was performed using Isoflurane (ISO) with EZ-SA800 Single Animal System. General anaesthesia was induced in the induction chamber with (3-5\%) ISO mixed with oxygen, maintained on mask with (1-1.5\%) ISO. All individuals received Tramadol for analgesia $20 \mathrm{mg} / \mathrm{kg}$. They were placed in dorsal recumbency on an electrical pillow to prevent hypothermia during the experiment and a $5 \mathrm{ml}$ syringe was positioned under the neck for a better exposure of the cervical region. Rats were prepared for surgical carotid cannulation in the ventral cervical region. The hair was clipped and the incision site was surgically prepared using betadine and chlorhexidine. The rat was covered using sterile drapes to protect the surgical field. Using 10 blade, a $2 \mathrm{~cm}$ skin incision was performed on the ventral middle line of the neck on the supra-clavicular region. A blepharostat as used to retract the skin. Using a Metzenbaum scissor and a soft forceps the left carotid was exposed by blunt dissection of the muscular layers and the omohyoid muscle was gently cut for a better exposure of the artery. A distal ligature was placed on the carotid artery together with the vagal nerve using an ophthalmologic needle holder and another loose one was placed proximally using a 4.0 polifilament wire. Using a Graham hook, the carotid was gently pulled up. A simple intravenous cannula (24G) was inserted and fixed with the proximal ligature, carefully, without obstructing the blood flow in the carotid cannula (Fig.1)A pressure monitoring set (produced by Edwards Life sciences) zeroed to the level of the right atrium was connected to the arterial catheter with an intravenous extender, filed with saline solution (0.9\%)and to the Dräger Infinity Delta monitor. The catheter was flushed with $0,1 \mathrm{ml}$ of $0,9 \%$ saline every 30 minutes to prevent the clot formation.

All rats were connected to a $0,9 \%$ saline solution used for catheter flush to prevent blood clotting. The skin was closed with a 4.0 wire in simple points. The changes in the vascular pressure are transmitted through the fluid filled catheters 


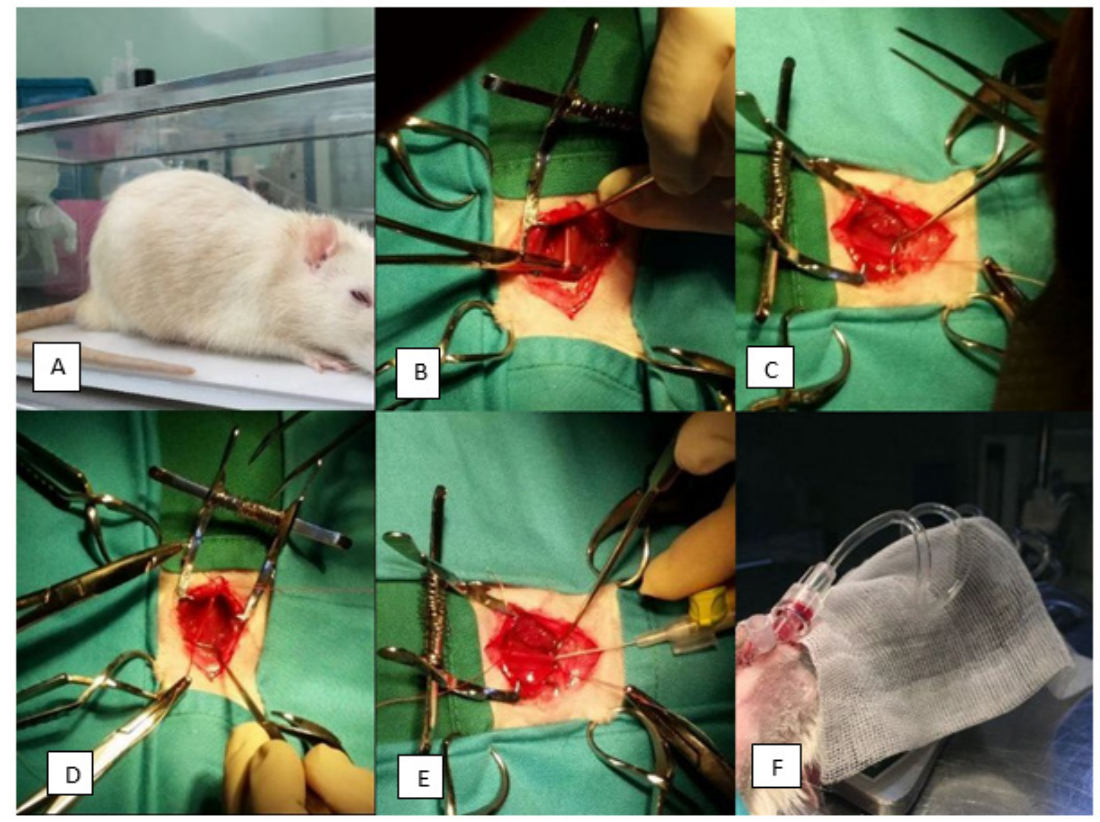

Fig.1. A - Induction of the anaesthesia, B - Blunt dissection of the carotid artery, C - fixing the distal ligature, D positioning the proximal loop for the loose ligature, E - inserting the cannula in the carotid artery, F - connecting the catheter to the transducer via the intravenous extender.
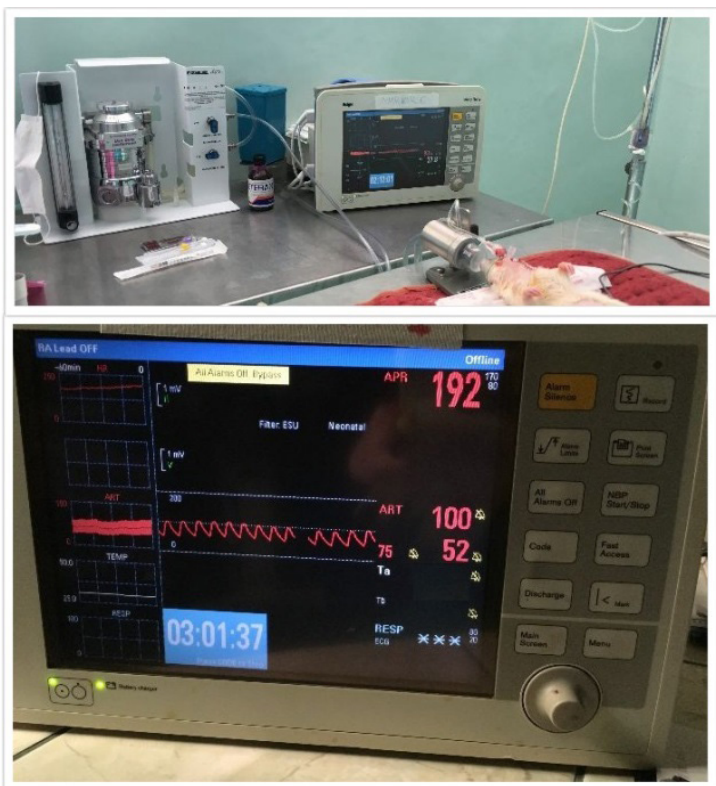

Fig.2. Connection of the rat to the transducer and the Dräger monitor to record the values with anaesthesia maintained

and convert into electrical signal represented by the hemodynamic waveforms (Fig.2). All subjects were maintained under anaesthesia for 8 hours and their MAP was registered every 30 minutes. The first value recorded was considered the control value. At the end of the experiment all the rats were sacrificed with an overdose of anaesthetic.

The uniformity of the subjects was tested trough standard deviation of the weight mean and it was validated by the coefficient of variation 
Table 1. Analysis of the control group in terms of individuals' weight

\begin{tabular}{|c|c|c|c|c|c|c|c|c|c|c|c|c|}
\hline Rat number & 1 & 2 & 3 & 4 & 5 & 6 & 7 & 8 & 9 & 10 & \multicolumn{2}{|c|}{ Batch specifications } \\
\hline Weight (g.) & 275 & 290 & 270 & 270 & 270 & 280 & 290 & 290 & 285 & 290 & $\begin{array}{l}\text { Average } \\
\text { (g.) }\end{array}$ & 281 \\
\hline Sex & $\mathrm{F}$ & $\mathrm{F}$ & $\mathrm{F}$ & $\mathrm{F}$ & $\mathrm{F}$ & $\mathrm{M}$ & $\mathrm{M}$ & $\mathrm{M}$ & $\mathrm{M}$ & M & SD/batch & 8.6023 \\
\hline $\begin{array}{l}\text { Average weight } \\
\text { (g.) females/ } \\
\text { males }\end{array}$ & & & 275 & & & & & 287 & & & S\%/batch & 3.06 \\
\hline $\begin{array}{c}\text { Standard } \\
\text { deviation (SD) } \\
\end{array}$ & & & 8.66 & & & & & 4.472 & & & \multirow[t]{2}{*}{$\mathrm{T}_{\text {calc. }} \mathrm{F} / \mathrm{M}$} & \multirow[t]{2}{*}{0.0332} \\
\hline S\% F/M & & & 3.15 & & & & & 1.56 & & & & \\
\hline
\end{tabular}

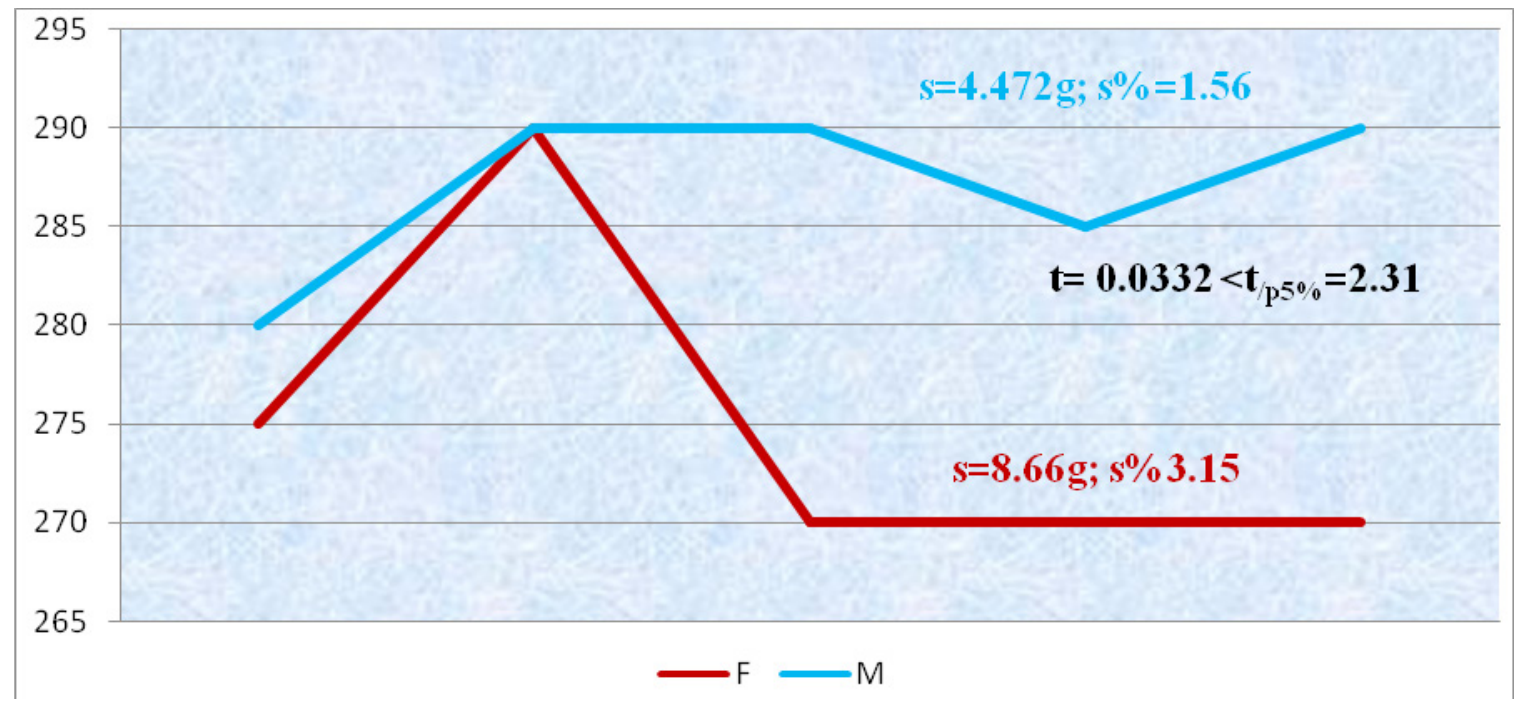

Fig.3. Comparative analysis of individuals female / male test group

value. It was also tested if there were statistical differences between the females and meals regarding the weight by t-test. The values recorded for MAP were processed with ANOVA, comparison with the control value trough Significant limit of differences (sld) for $\mathrm{p}=5 \% ; 1 \% ; 0,1 \%$, and multiple comparison by Duncan test.

\section{RESULTS AND DISCUTIONS}

The average weight of the rats used in the batch is $281 \mathrm{~g}$, the standard deviation (SD) recorded was $8.6 \mathrm{~g}$. The coefficient of variation calculated $(\mathrm{s} \%=3.06 \%)$ indicates a reduced variable inside the lot. Test group consisted in both females and males. Females average weight is
$275 \mathrm{~g}$, with a standard deviation of $8.66 \mathrm{~g}$ and low coefficient of variation $(s \%=3.15)$. The average male weight is $287 \mathrm{~g}$, with a standard deviation of $4.472 \mathrm{~g}$ and coefficient of variation of their weight is $1.56 \%$. Both females and males in the group have weight within normal limits, the degree of variation expressed by the coefficient of variation (s\%), being reduced. We compared by Student test $\left(\mathrm{t}_{\text {calc }}\right)$ the recorded weights in females with the ones recorded in males. $t_{\text {calc }}$ value $=0.0332$, indicating a statistically insignificant difference between males and females. It can be concluded that the particular batch is homogenous, without statistically significant deviations in terms of weight between individuals. 


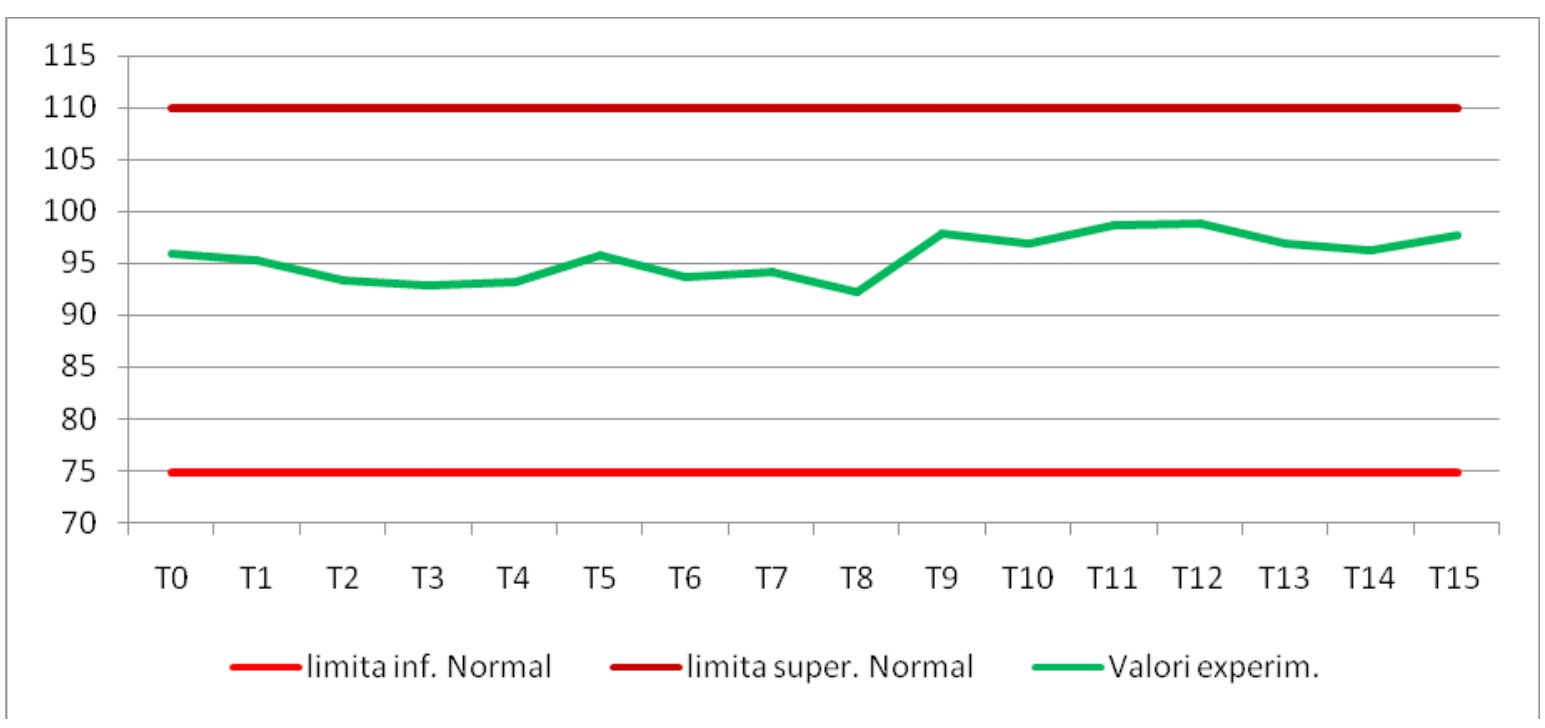

Fig.4. MAP averages/batch recorded during tests

Table 2. MAP analysis of variance values recorded during the tests, for the control group

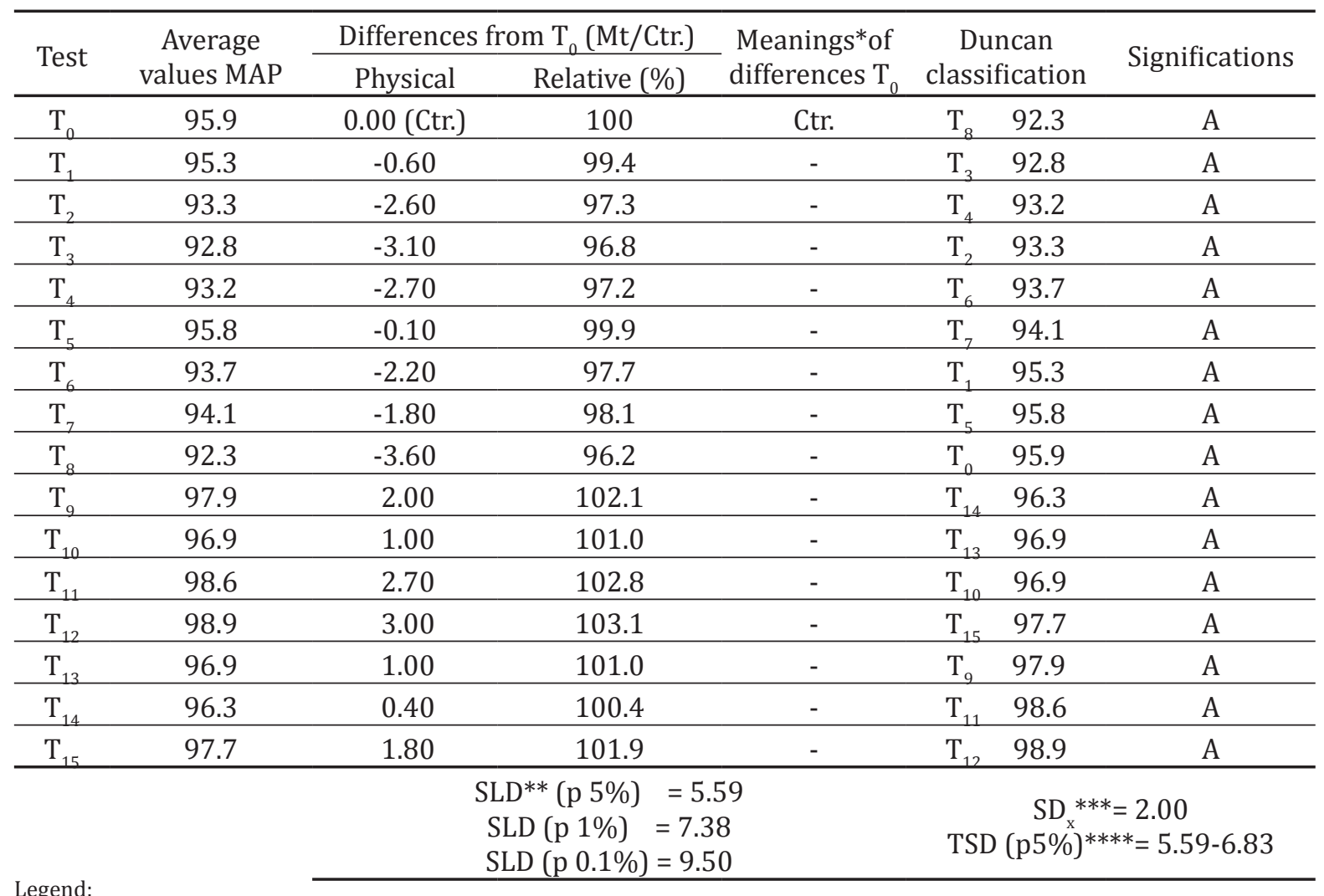

Legend:

A = unssignificant differences

${ }^{* *}$ SLD $=$ Significant limit of differences

*** $\mathrm{SD}=$ Standard deviation of the mean

$* * * *$ TSD $=$ Theoretical Significant Differences

statistically significant differences from the control, denoted by -; statistically significant differences from the control, or marked with a *; distinct differences statistically significant compared to the control and marked with ${ }^{* *}$ oo or statistically significant differences from the control, denoted by ${ }^{000}$ or ${ }^{* * *}$.

** SLD = Significant limit of differences

*** SDX $=$ Standard deviation of the mean

**** TSD $=$ Theoretical Significant Differences 
MAP recorded at the beginning of the experiment has values between 75 and 110, their average was 95.9 with a standard deviation of 12.52 (Fig 4). MAP variation in the control group during the 15 times recording in the experiment is within the normal range for rats (Fig 4).

MAP analysis of variance values recorded in the control group (Table 2) applied to the 15 tests show that from the initial average (95.9) recorded decreases or increases in MAP statistically permissible limits. Differences averages calculated for all tests in the experiment, compared to the initial average MAP are not statistically significant, $p=5 \%$, which is between - 3.6 and +3.0.; while differences limit calculated for the 3 levels of confidence are summarized between 5.59 and 9.5 .

The data classified and verified through multiple comparisons, using the Duncan test (Table 2: Duncan Classification and meanings) certifies the homogeneity values of MAP and consequently the uniform behavior of the control group, so that any significance check of differences between all variants tested, the result is below the TSD (p5\%).

Monitoring the hemodynamic evolution of an illness for a clinical model to investigate different therapeutic approaches needs vascular access. Arterial catheterisation provides systemic pressure monitoring. Recording MAP during the experiment on rats can be very helpful and could enhance the animal survivability during the experiments and can provide grateful information regarding the evolution of the pathologies that are investigated. Measuring the IBP by carotid cannulation is accurate and quantifiable, individual variation may be observed but with a correct technique, the obtained vales are reliable.

The most critical part of the procedure is represented by the catheter insertion. The catheter tip must be of soft material, no to damage the vessel wall, but the body of the catheter needs to be stiffer so it can advance into the vessel without angulating. The needle from the catheter must be only $1 \mathrm{~mm}$ longer than the cannula, otherwise penetration of the artery on both sides can occur. Close attention must be paid when connecting the cannula to the transducer via the intravenous extender not to have any air bubbles that can produce lung, brain or other organ embolism.
Dissecting the vagus nerve it is difficult technique to perform therefore in our study we legated the nerve together with the carotid artery. We did not encounter any vagal stimulation consecutive to vagal nerve ligation as other author describe (Feng et al., 2015; Parasuraman, 2012).

Inhalatory anaesthesia with isoflurane is suitable for monitoring MAP in rats, the values obtained were the same as other described in their research (7). The advantage of this technique is that it is easy to implement, the materials used are accessible, but it has the disadvantage that the catheter cannot be place in situ for a longer period of time to monitor MAP for longer periods and because of that the rats needs to be anesthetised during the whole experiment.

\section{CONCLUSIONS}

Carotid cannulation with the technique described provides uniform and reliable values for mean arterial pressure. Isofluran anaesthesia for rats is suitable for recording mean arterial pressure, the values obtained were in the value range of the species. This technique can be applied to acute experiments, for a short period and it demands anaesthesia even in the monitoring period.

\section{REFERENCES}

1. Feng J, Fitz Y, Li Y, Fernandez M, Puch IC, Wang D, Solomon SB (2015). Catheterization of the carotid artery and jugular vein to perform hemodynamic measures, infusions and blood sampling in a conscious rat model. Journal of visualized experiments: JoVE, (95).

2. Faunt KK (2008). Anaesthesia for pet practitioner $2^{\text {nd }}$ ed. Banfield, USA $21 \mathrm{p}$

3. Karwacki Z, Kowianski P, Witkowska M, Karwacka M, Morys J (2006). The technique of inhalation anaethesia in experimental investigation in the rat. Folia MorphologicaWARSZAWA-english edition, 65(4): 414.

4. Ordodi VL, Mic FA, Mic AA, Toma O, Sandesc D, Paunescu $\mathrm{V}$ (2005). A simple device for invasive measurement of arterial blood pressure and ECG in the anesthesized rat. Timisoara Med J, 55(8): 35-7.

5. Parasuraman S, Raveendran R (2012). Measurement of invasive blood pressure in rats. Journal of Pharmacology and Pharmacotherapeutics, 3(2):172.

6. Plehm R, Barbosa ME, Bader M. (2006). Animal models for hypertension/blood pressure recording. Methods Mol Med.; 129:115-26. 
7. Wang, Cong Y, Li J, Li X, Li B, Qi S (2013). Comparison of invasive blood pressure measurements from the caudal ventral artery and the femoral artery in male adult sd and wistar rats. PloS one, 8(4), e60625.

8. Novak W (2003). Anaesthesia for Pet Practitioner, Banfield, USA 68-70, 90-91 p
9. Tranquilli WJ, Thurmon JC, Grim KA (2007) Lumb\&Jones's Veterinary Anaesthesia and Analgesia. $4^{\text {th }}$ ed. Blackwell Publishing 355-383, 533-547 p

10. Muir WW (2008). Manual de Anaesthesia Veterinaria $4^{\text {th }}$ ed. Elsevier Espana, 164-194 p 